\title{
Tuorevihannesten prosessoinnin hygienia ja ympäristövaikutukset
}

\author{
Marja Lehto $^{1}$, Risto Kuisma ${ }^{2}$, Jenni Määttä ${ }^{2}$, Hanna-Riitta Kymäläinen ${ }^{2}$, Ilkka Sipilä ${ }^{1}$, Maarit Mäki ${ }^{3}$ \\ ${ }^{1)}$ MTT Kotieläintuotannon tutkimus, Vakolantie 55,03400 Vihti, marja.lehto@mtt.fi, \\ ilkka.sipila@mtt.fi \\ ${ }^{2)}$ Helsingin yliopisto, Agroteknologian laitos, PL 28 (Koetilantie 3), 00014 Helsingin \\ yliopisto, risto.kuisma@helsinki.fi, jenni.maatta@helsinki.fi. \\ hanna-riitta.kymalainen@helsinki.fi \\ ${ }^{3)}$ MTT Biotekniikka- ja elintarviketutkimus, ET-talo, 31600 Jokioinen, \\ maarit.maki@mtt.fi
}

\section{Tiivistelmä}

Viime vuosina elintarvikealalla on noussut erityisen huomion kohteeksi tuorevihannesten turvallisuus. Vihanneksilta vaaditaan entistä pitempää säilyvyyttä, mutta mikrobiologisen turvallisuuden takaavista tuotantomenetelmistä ei ole riittävästi luotettavaa näyttöä. Vuonna 2009 käynnistyneen Tuorevihannesten hygienia (Tuovi) -hankkeen tavoitteena on tuorevihannesten viljely- ja tuotantoprosessien kehittäminen. Vihanneksista tarkastellaan erityisesti porkkanaa ja salaattia. Hankkeessa tarkastellaan koko tuotantoketjua, raaka-aineen tuotantoa, varastointia, prosessointia ja kylmäketjua aina vähittäiskauppaan saakka. Hankkeessa selvitetään tuotantotilojen, raaka-aineiden ja tuotteiden hygieenistä laatua, sekä kehitetään menetelmiä ja erilaisia teknologisia ratkaisuja tuorevihannesten hygieniatason nostamiseksi ja ylläpitämiseksi. Hankkeessa selvitetään myös vihannesten prosessoinnista aiheutuvia ympäristövaikutuksia. Tavoitteena on prosesseja kehittämällä vähentää syntyvien jätteiden ja jätevesien määrää sekä minimoida niistä aiheutuvaa riskiä ympäristölle ja ihmisten terveydelle.

Haitalliset mikrobit voivat päätyä vihanneksiin peltomaasta tai kasteluvedestä. Mikrobit voivat olla kasvin pinnalla, mutta myös ehjän kasvin sisällä, joten mikrobien pääsy kosketuksiin kasvisten kanssa voi olla riski kuluttajien turvallisuudelle. Suomessa on viime vuosina todettu mm. Yersiniaepidemioita, joiden yleistymisen estämiseksi tarvitaan lisätutkimusta tuotanto-olosuhteista ja prosessihygieniasta. Alkuvaiheessa ongelmia voidaan ehkäistä noudattamalla hyviä viljelymenetelmiä (GAP, Good Agricultural Practice) ja omavalvontaa. Nämä ohjeet sisältävät toimenpiteitä, jotka kohdistuvat mm. kasteluveteen, lannoitteisiin, biojätteisiin, työntekijöiden terveyteen, hygieniaan, tuotantolaitoksiin ja käsittelytiloihin, pakkauksiin, kuljetuksiin, jakeluun sekä jäljitettävyyteen. Mikrobit voivat päästä vihanneksiin myös vihannesten prosessoinnin aikana. Omavalvonta, jossa hyödynnetään mikrobiologisia testausmenetelmiä, on tärkeä työväline prosessien turvallisuuden seurannassa. Tämän lisäksi voidaan tarvittaessa käyttää erilaisia teknisiä käsittelymenetelmiä. Tuorevihannesten jatkojalostuksessa on tarpeen soveltaa uutta tutkimustietoa vihannesten mikrobiologisen laadun turvaamiseksi.

\section{Asiasanat \\ tuorevihannes, hygienia, prosessointi, jätteet, jätevedet}




\section{Johdanto}

Haitalliset mikrobit voivat päätyä vihanneksiin peltomaasta tai kasteluvedestä. Viime vuosina tuoretuotteita, kuten jäävuorisalaattia (Nuorti ym, 2004) ja porkkanaa (Jalava ym., 2006), on epäilty vatsatautiepidemioiden aiheuttajiksi, mutta tartuntareittejä ei ole pystytty aina varmuudella osoittamaan. Ei ole riittävän hyvin tiedossa, missä olosuhteissa patogeenit selviytyvät ja pääsevät vihanneksiin. Yersinia-suvun bakteereita on esiintynyt enemmän keväällä ja talven yli varastoiduissa juureksissa kuin tuoreissa vihanneksissa loppukesällä ja syksyllä (Niskanen 2007). Porkkanassa tavattu Yersinia pseudotuberculosis-bakteeri aiheutti laajalle levinneen epidemian Etelä-Suomessa elo-syyskuussa 2006. Vihannesten jatkojalostus on lisääntynyt viime vuosina monissa Euroopan maissa (Lehtinen, 2006). Suomessa on satoja vihannestiloja, jotka käsittelevät 50 - 1000 tonnia vihanneksia vuodessa. Toiminnasta muodostuu huomattavia määriä sivutuotteita ja jätevesiä, joiden käsittely tiloilla kiristyvien ympäristövaatimusten mukaisesti on haasteellista.

Vihannesten prosessointi on ympäristöluvanvaraista toimintaa. Ympäristöluvissa asetetaan vaatimukset yrityksen jäteveden ja jätteiden käsittelylle. Jätevesien määrä ja laatu vaihtelee suuresti riippuen käsiteltävästä raaka-aineesta, käsittelymenetelmästä ja -määrästä sekä veden käytöstä. Runsaasti orgaanista ainetta sisältäviä jätevesiä muodostuu juureskuorimolla $5-50 \mathrm{~m}^{3}$ päivässä. HELCOM (1996) on antanut elintarviketeollisuudelle suosituksen, joka sisältää ohjearvot laitoksille, jotka tuottavat jätevettä yli $25 \mathrm{~m}^{3}$ vuorokaudessa. Käsitellyn jäteveden pitoisuuksien tulisi täyttää seuraavat vaatimukset: $\mathrm{BOD}_{7}<30 \mathrm{mg} \mathrm{l}^{-1}, \mathrm{COD}_{\mathrm{Cr}}<250 \mathrm{mg} \mathrm{l}^{-1}$, fosfori $\left(\mathrm{P}_{\text {tot }}\right)<2 \mathrm{mg} \mathrm{l}^{-1} \mathrm{ja} \mathrm{NH}_{4}-\mathrm{N}<10$ $\mathrm{mg} \mathrm{l}^{-1}$. Myös pienten puhdistamoiden on päästävä samalle tasolle jäteveden puhdistuksessa. Toiminnasta muodostuva kasvijäte tulee myös käsitellä ennen kun sitä voidaan hyödyntää maanparannusaineena.

Tämän tutkimuksen eräänä taustatekijänä ovat olleet Yersinia-epidemiat, joiden aiheuttajaksi on voitu osoittaa prosessoitu porkkana (Jalava 2006). Epidemioiden välttämiseksi viranomaiset ovat laatineet suosituksia porkkanoiden varastoijille, viljelijöille, jatkojalostusyrityksille sekä laitoskeittiöille (Evira 2009b). Tutkimuksen tavoitteena on parantaa kotimaisen vihannestuotannon toimintaedellytyksiä vihannesraaka-aineen sekä lopputuotteen laatua parantamalla, prosesseja kehittämällä sekä ympäristövaikutuksia vähentämällä.

\section{Aineisto ja menetelmät}

Hankkeessa kehitetään tuorevihannesten, erityisesti porkkanan ja salaatin, koko tuotantoketjua, johon kuuluvat raaka-aineen laadun hallinta, viljely, prosessointi, puhdistus- ja dekontaminaatiotekniikat, prosessivesien käsittely, raaka-aineiden ja tuotteiden varastointi, kuljetus ja tukkukauppa. Tutkimuksen pääkohdat on esitetty kuvassa 1.

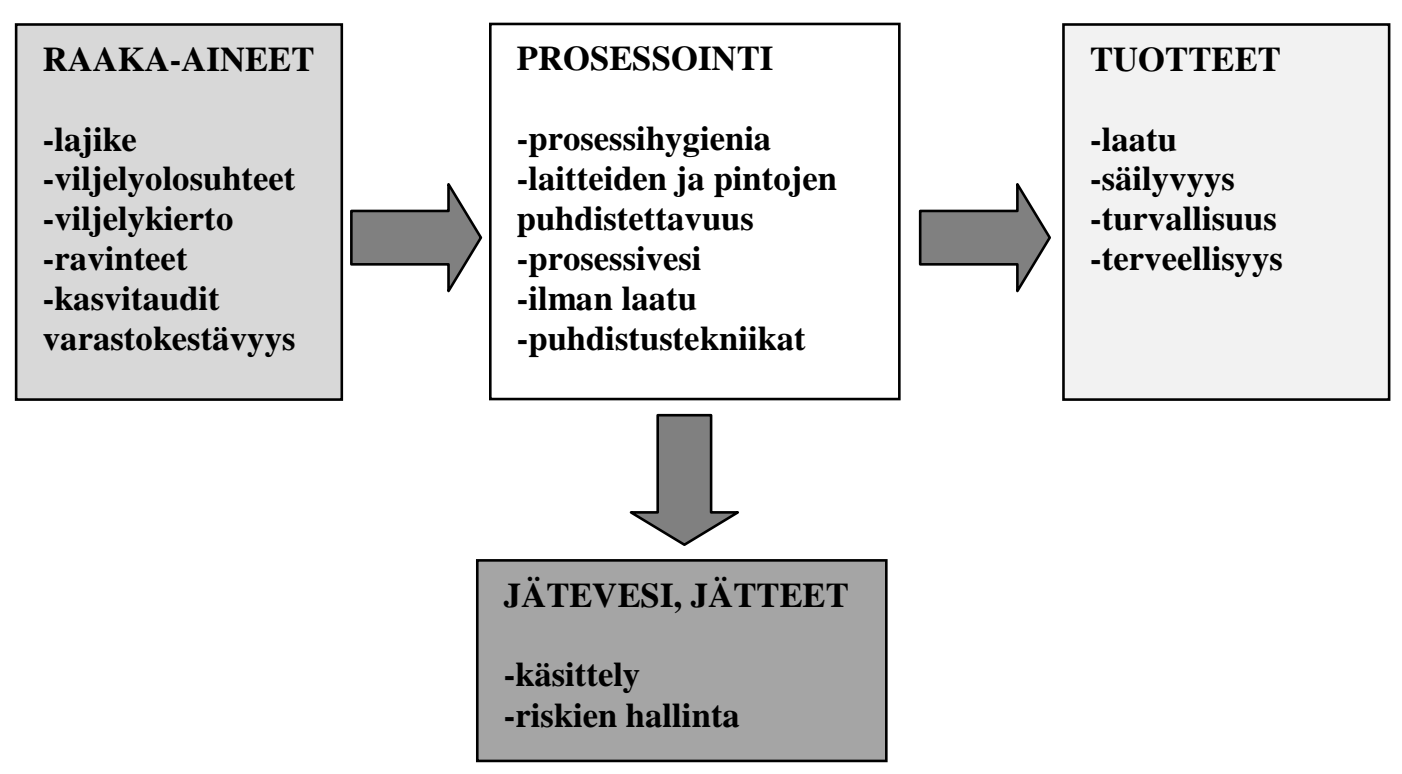

Kuva 1. Tutkimuksen painopisteet. 
Tuovi-hankkeen alkuvaiheessa on selvitetty jatkojalostusyritysten hygieniatasoa ja arvioitu mikrobiologista turvallisuutta kuudessa porkkanaa ja salaattia jatkojalostavassa yrityksessä. Hankkeessa tehdään myös porkkanan viljely- ja varastointikokeita, jotka on aloitettu keväällä 2009. Hankkeessa on mukana erilaisia yrityksiä. Toiset yritykset sekä tuottavat raaka-aineen että prosessoivat sen valmiiksi tuotteiksi, toiset taas jatkojalostavat esikäsiteltyä raaka-ainetta. Erilaisia tuotantoketjuja on esitetty kuvassa 2.

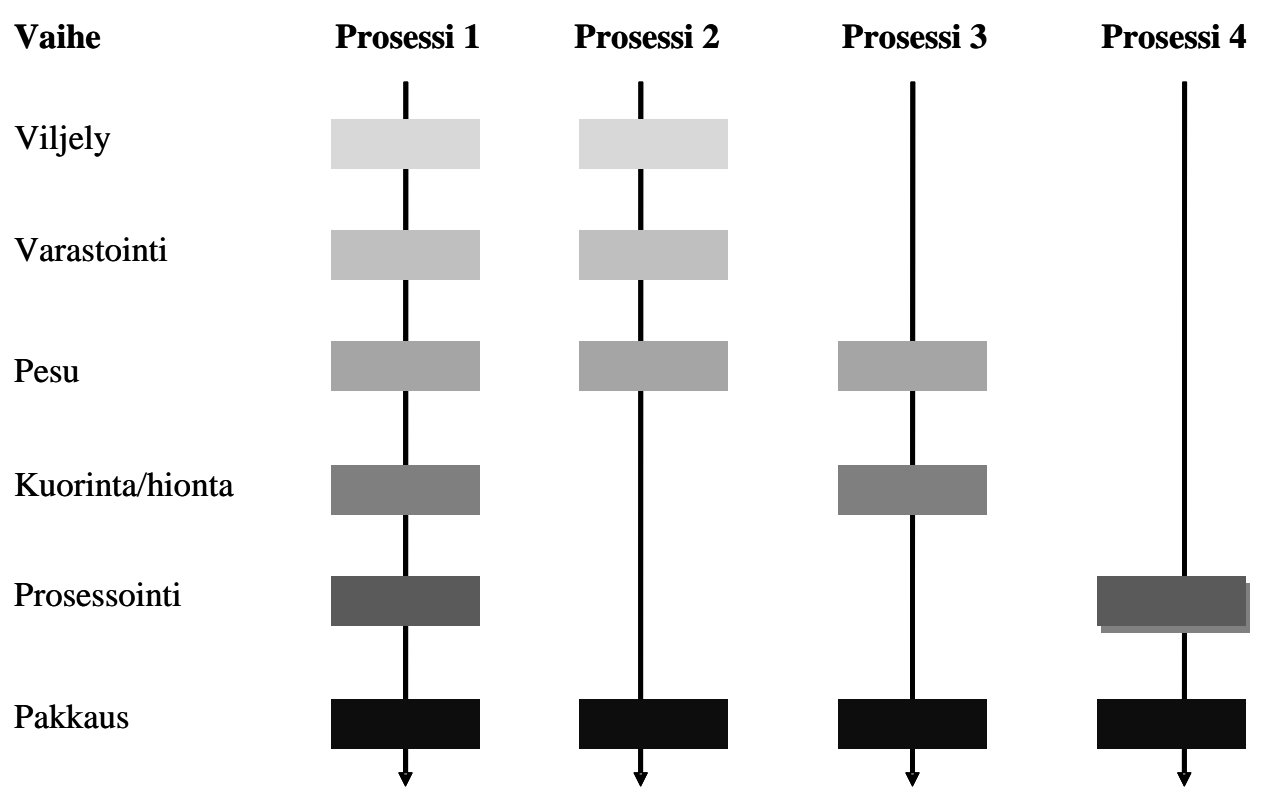

Kuva 2. Esimerkkejä tuotantoketjuista ja yritystyypeistä

Kasviksia jatkojalostavien yritysten hygieniatason määrittämiseksi ja ongelmakohtien selvittämiseksi haastateltiin ensin yrityksen henkilökuntaa ja keskusteltiin erilaisista toimintaan liittyvistä asioista. Näytteenottokohdat dokumentoitiin ja kuvattiin. Tämän pohjalta tehtiin varsinainen näytteenottosuunnitelma, jonka mukaisesti hygieniakartoitus toteutettiin. Jatkojalostuslaitoksen yksilölliset piirteet pyrittiin ottamaan huomioon näytteenottotilanteessa.

Pinta- ja ympäristönäytteet otettiin tilojen normaalin puhdistuksen jälkeen. Lisäksi otettiin raakaaine- ja tuotenäytteet mikrobiologisia tutkimuksia varten. Ilman ja pintojen hygieenistä tasoa tutkittiin erilaisilla määritysmenetelmillä. Orion Diagnostican Hygicult® TPC -kontaktilevyjä käytettiin aerobisten mikrobien kokonaismäärän määritykseen. Hygicult ${ }^{\circledR} \mathrm{E} / \beta$-Gur -kontaktilevyjä käytettiin enterobakteerien ja ß-glukuronidaasi-entsyymejä tuottavien lajien kokonaismäärän määritykseen. Escherichia coli -kannoista $90 \%$ on ß-glukuronidaasiaktiivisia. Myös Salmonella, Edwardsiella, Shigella ja Yersinia ovat ß-glukuronidaasia tuottavia lajeja. Hygicult ${ }^{\circ}$ Y\&F -kontaktilevyjä käytettiin hiivojen ja homeiden kokonaismäärän määritykseen. ATP-bioluminesenssi mitattiin luminometrisesti HY-LiTE®2-laitteella (Merck KgaA, Saksa). Ilmassa olevien mikrobien lukumäärän määritykseen käytettiin MAS-100 -keräintä (Merck Eurolab).

Muodostuvien jätteiden ja jätevesien laatua ja määrää arvioitiin erityyppisissä prosesseissa. Vihanneksia käsittelevien laitosten tuotannosta tulevista jätevesistä kerättiin viikon kokoomanäyte, josta määritettiin BOD, COD, kokonais- $\mathrm{N}$, kokonais-P, kiintoaine ja $\mathrm{pH}$. Jätevesien mikrobiologisen laadun selvittämiseksi kartoitettiin mikrobeja, jotka kuvaisivat parhaiten jätevesien laatua.

Raaka-aine- ja tuotenäytteistä tutkittiin kokonaismikrobimäärä, koliformisten bakteerien, hiivojen, homeiden, E. colin sekä enterobakteerien määrä. Tuotannosta otetuista prosessivesinäytteistä tutkittiin koliformisten bakteerien, fekaalisten koliformien sekä E. colin määrä. Lisäksi sekä vihanneksista että vesinäytteistä tutkittiin Yersinia enterocolitica- ja $Y$. pseudotuberculosis -bakteerien mahdollista esiintyvyyttä. 


\section{Tulokset ja tulosten tarkastelu}

Hygieniakartoitusten tulokset sekä mahdolliset parannusehdotukset ja suositukset hygieenisen laadun parantamiseksi yrityksessä esitettiin yritysten edustajille. Huomiota tulisi kiinnittää erityisesti erilaisten laitteiden ja pintojen puhdistettavuuteen, tilojen säännölliseen ja perusteelliseen puhdistukseen sekä desinfiointiin, työntekijöiden koulutukseen ja työskentelytapoihin. Yritysten toiminnassa, tiloissa ja prosesseissa oli suuria eroja. Myös hygieniatasossa oli eroja yritysten välillä. Yritykset käsittelivät sekä kotimaista että ulkomaista alkuperää olleita raaka-aineita. Valmiiden tuotteiden mikrobiologisen laadun todettiin yleisesti olevan hyväksyttävällä tasolla. Kaikille tutkituille mikrobiryhmille ei tosin ole tällä hetkellä olemassa virallisia raja-arvoja (Evira 2009a). Y. enterocolitica-bakteeria esiintyi sekä tuotteissa että prosessivesissä, mutta patogeenisiä kantoja ei tutkimuksessa todettu. Apatogeenisten yersinioiden runsas esiintyminen voi kuitenkin joissakin tapauksissa olla merkkinä myös mahdollisten patogeenisten yersinioiden esiintymisestä (Niskanen 2007). Riittävästä pesu- ja huuhteluvesien vaihtamisesta ja laitteiden puhdistuksesta tulee huolehtia, jotta voidaan vähentää lopputuotteiden kontaminoitumisriskiä ja ei-toivottujen bakteerien siirtymistä lopputuotteeseen. Y. pseudotuberculosis-bakteeria ei todettu tutkituissa tuotteissa.

Kasvisten prosessoinnissa syntyvien jätevesien laatua tarkastellaan eri yrityksissä, kiintoaineen ja orgaanisen aineen pitoisuuksia on esitetty taulukossa 1. Jätevesien mikrobiologisen laadun selvittämiseksi on tehty alustavaa tutkimusta ja selvitetty näytteiden käsittelymenetelmiä.

Taulukko 1. Eri prosesseissa syntyvien jätevesien kiintoaineen ja biologinen hapenkulutuksen $\left(\mathrm{BOD}_{7}\right)$ pitoisuuksia. Prosessit 1-4 on esitetty kuvassa 2.

\begin{tabular}{lll}
\hline Prosessit & Kiintoaine $\left(\mathrm{mg} \mathrm{l}^{-1}\right)$ & $\mathrm{BOD}_{7}\left(\mathrm{mg} \mathrm{l}^{-1}\right)$ \\
\hline Prosessi 1 & $1000-2000$ & $2000-4000$ \\
\hline Prosessi 2 & $1000-2000$ & $<1000$ \\
\hline Prosessi 3 & $1000-2000$ & $2000-4000$ \\
\hline Prosessi 4 & $<200$ & $<1000$ \\
\hline
\end{tabular}

\section{Johtopäätökset}

Tuovi-hanke on alkanut vuoden 2009 alussa ja jatkuu vuoden 2011 loppuun. Hankkeen alkuvaiheessa on mittausten ja muiden selvitysten avulla kartoitettu lähtötilanne tuorevihannesten jatkojalostusta harjoittavissa yrityksissä. Tältä pohjalta lähdetään kehittämään prosessien turvallisuutta ja ympäristönäkökohtia.

\section{Kirjallisuus}

Baltic Marine Environment Protection Commission, Helcom Recommendation 17/10, Basic principles for realization of BAT and BEP in food industry, Helsinki. www.helcom.fi/Recommendations/en_GB/rec17_10/ (1996).

European Parliament and of the Council, EU water framework directive 2000/60/EC. Directive of the European Parliament and of the Council of 23.10 .2000 establishing a framework for Community action in the field of water policy (2000).

Evira 2009a. Eviran ohje 10501/1. Elintarvikkeiden mikrobiologiset vaatimukset. Komission asetuksen (EY) No 2073/2005 soveltaminen. Ohje elintarvikealan toimijoille. http://www.evira.fi/uploads/WebShopFiles/1243849246290.pdf. Liite 5.

Evira 2009b. Eviran suositus toimenpiteistä Yersinia pseudotuberculosis-bakteerin esiintymisen vähentämiseksi kotimaisessa porkkanassa. Dnro 4324/0405/2009. 4.6.2009. http://www.palvelu.fi/evi/files/72_653_253.pdf 
Jalava K., Hakkinen M., Valkonen M., Nakari U-M., Palo T., Hallanvuo S., Ollgren J., Siitonen A. \& Nuorti J.P. 2006. An outbreak of gastrointestinal illness and erythema nodosum from grated carrots contaminated with Yersinia pseudotuberculosis. Journal of Infectious Diseases 194: 1209-1216.

Lehtinen S. 2006. Parhaat käyttökelpoiset tekniikat (BAT) perunankuorimoiden jätteiden käsittelyssä: käytäntöjä Euroopan maista. (Best available techniques (BAT) of the treatment of potato peeling wastes: practises in Europe). Lappeenranta University of Technology, 93 pp.

Lehto, M., Sipilä, I, Sorvala, S., Hellstedt, M., Kymäläinen, H-R, Sjöberg, A., 2009. Evaluation of on-farm biological treatment processes for wastewaters from vegetable peeling. Environ. Tecnol. 30,: 3-10.

Niskanen, T. 2007. Yersinia enterocolitican ja Yersinia pseudotuberculosiksen sekä apatogeenisten Yersinialajien esiintyminen kotimaisissa kasviksissa. Evira, $17 \mathrm{~s}+$ liitteet $9 \mathrm{~s}$. www.evira.fi/.../valvonta.../yhteenveto_2005-2006_yersiniaprojekti.pdf

Nuorti J.P, Niskanen T., Hallanvuo S., Mikkola J., Kela E., Hatakka M., Fredriksson-Ahomaa M., Lyytikäinen O., Siitonen A., Korkeala H. \& Ruutu P. 2004. A Widespread Outbreak of Yersinia pseudotuberculosis O:3 Infection from Iceberg Lettuce. Journal of Infectious Diseases 189: 766-774. 